\title{
Why and How to Study a Snowcover
}

\author{
WiLLIAM O. PRUITT, JR.
}

Taiga Biological Station and Department of Zoology, University of Manitoba, Winnipeg, Manitoba R3T 2N2 Canada

Pruitt, William O., Jr. 2005. Why and how to study a snowcover. Canadian Field-Naturalist 119(1): 118-128.

Specialized terminology, duration, thickness, hardness, density of the snowcover of taiga and tundra are described. Methods for detailed study of these characteristics are given, with description and use of simple as well as specialized instruments and techniques in relation to winter ecology of mammals and birds.

Key Words: snow, snowcover, taiga, tundra, snow ecology, winter ecology, boreal ecology, snow instruments, snow terminology.

Why is it necessary to study and record the details of a snowcover? Is not knowledge of the thickness of the cover (or even just its presence or absence) sufficient to explain the use or lack of use of an area by animals? In this paper I will show how details of a snowcover affect not only the presence or absence of a species but also how a species can use the snowcover, how it is affected by the variations in the snowcover morphology or sometimes is induced to emigrate from a region because of characteristics of only one layer in the snowcover

Moreover, some species move down from the surface of the snowcover or up into the snowcover itself for varying periods of time. For some species the snowcover acts as a hindrance to travel or to obtaining food from under it, to others as a blanket protecting life from the deep cold of Full Winter (Pruitt 1957, 1960). This paper will also describe and review widely-accepted, as well as specialized, descriptors, instruments and measuring techniques. These techniques give one the tools for basic descriptive analyses of snow features. Sturm (1992) demonstrated, based on such a framework, an analysis of heat flow through taiga api as affected by qali fall and bare qamaniq.

\section{Terminology}

The English language evolved in a misty, maritime climate where snow was an uncommon occurrence, consequently it is woefully deficient in words representing snow phenomena. The "scientific" languages (Latin and Greek) are derived from cultures which had even less familiarity with snow and its various forms than did English. Therefore, it seems best to use precise words that designate features and concepts from cultures that have evolved closer ecological links with snow than our Euro-Canadian one. Familiarity with these words exposes us to a whole new world of snow. The participants in the Scandinavian-Canadian Field Workshop on Rangifer-Snow Ecology (Pruitt 1971) resolved “...to assemble all known snow terms in all northern languages and to illustrate each term with a photograph or accurate drawing. We believe that publication of such a lexicon would materially advance the study of boreal ecology. We invite submission of snow terms and pho- tographs for possible inclusion in the lexicon.” Table 1 consists of some words from such cultures that my students and I have found especially useful in our studies of snow ecology (Pruitt 1978, 1979, 1999). The simplified spelling and pronunciation of these words is given, enclosed in brackets, immediately after the first use in this paper.

There are four major qualities of a snowcover, particularly as they affect living organisms: Duration, Thickness, Hardness, and Density (Pruitt 1984a). The latter two characteristics enter into calculations of "snow water equivalent" and are influenced primarily by wind and the occurrence of winter thaws or freezethaw cycles. Thus there are four combinations that generally agree with four major geographic types of snowcover:

- steppes and coastal regions with freeze-thaw and wind,

- tundra with wind and no freeze-thaw,

- inland southern regions with freeze-thaw but no wind,

- taiga with no freeze-thaw and no wind.

This classification has recently been confirmed in general by Sturm et al (1995). Confusion sometimes still exists between "arctic" and "taiga" snow processes, especially concerning the known effects of snowcover on large mammals such as wolves, foxes and caribou (Olsson et al. 2003).

\section{Duration}

The onset and disappearance of a snowcover, whether taiga api [ah-PEE] or tundra upsik [OOP-sik] (Table 1), are accompanied almost always by fluctuations in snowcover over the landscape. Inexperienced researchers have a tendency to fail to record the details of exact position and shape of the transitory spots where api first forms and where it lingers longest. One should make an effort to record these characteristics, preferably by detailed sketches including measurements of the spots and their exact locations, as well as times they occur. These spots and connecting areas will probably be where the Hiemal Threshold (Pruitt 1957) will occur first. The sequence of Fall Thermal Overturn, Fall Critical Period, Hiemal Threshold, Full Winter, Hiemal Termination, Spring Critical Period, Spring Thermal Over- 
turn (Pruitt 1978, Figure 4-1; 1984b) are all important events in the cycle of the seasons for the plants and animals of the forest floor. The duration and intensity of the fall and spring critical periods can govern survival of populations of small mammals (Whitney and Feist 1984). For some individuals or age-classes of a population of Caribou (Rangifer tarandus), overwinter survival seems to be a race between decreasing body mass ("loss of condition") and duration of the snowcover.

One of the important environmental factors affecting snow is wind. If wind is lacking, the complex, sixarmed snow crystals drift down and settle undisturbed on other crystals which have preceded them, or onto the ground and short vegetation. Here, over time, they will undergo metamorphosis driven by the heat and moisture rising from the earth below (Schemenauer et al. 1981; Seligman 1936). This heat and moisture will modify the snow crystals by subliming water molecules from the attenuated tips of the arms and redepositing them on colder crystals farther from the earth. The bottom-most crystals are the oldest and, therefore, have undergone this process the longest. Consequently, they are the most modified. Sometimes they are completely eroded away and their molecules have been redeposited higher up in the snow cover. Because of the physics of snow crystals the modified ones are in the shape of sixsided scrolls or pyramids.

They can reach $10 \mathrm{~mm}$ or more in size and, upon magnification, they look as if they are made from tiny glass logs (Figure 1). The metamorphosed layer can extend $10 \mathrm{~cm}$ or more up into the cover and is properly known as pukak [POO-kak]. This layer is of great importance to subnivean mammals and winter-active invertebrates. In some subalpine or northern taiga regions where there is intense heat-loss from the snowcover surface, almost all the snowcover can consist of pukak.

Such is the idealized situation, with the api affected only by the heat and moisture rising from the earth, and with little or no heat coming from the supranivean air. In temperate and maritime climates where warm, moist air masses can intrude on the winter climate there can be heat and moisture gradients moving downwards as well. In these conditions pukak may not form, or may be severely modified (Pruitt 1984b). On the island of Newfoundland, with its relatively warm, wet, yet snowy, maritime climate, I found pukak in only a few sites near the upper limit of trees in the Long Range Mountains. I suspect that the general lack of pukak is as reasonable an explanation for the island's markedly depauperate small mammal fauna as is any species' inability to cross the Strait of Belle Isle (Pruitt 1968). Indeed, I now believe that pukak, not only its physical condition as a safe winter habitat for small mammals and invertebrate life, but as an indicator of general winter conditions for all boreal life deserves a great deal more research attention than it has had in the past.
TABLE 1. Specialized snow terminology of some northern peoples. Transliterations in parentheses after aboriginal word indicate pronunciations in general English sounds. (Capitalized syllable means stress accent; "q" indicates a hard, glottal stop)

\begin{tabular}{ll}
\hline \hline English & $\begin{array}{l}\text { Kobuk Valley (Alaska) } \\
\text { Inupiat }\end{array}$ \\
\hline Snow & anniu (ah-NEE-u) \\
Snow on trees & qali (KAH-lee)
\end{tabular}

Dense crystals, moist air hitting very cold surface

Snow on the ground,soft fluffy taiga snow

kanik (KAH-nik)

api (ah-PEE)

Base of snowcover, with large, pyramidal crystals

Hard, wind-beaten snow (tundra or prairie)

Drifting snow

Smooth snow surface of very fine particles

Rough snow surface of large particles

Sun crust

Drift downwind of an obstruction

Space between drift and obstruction causing it

Arrowhead-shaped drift moving over upsik

Wind-eroded upsik from kalutoganik

Irregular surface caused by differential erosion

Bowl-shaped depression in api around base of tree

pukak (POO-kak)

upsik (OOP-sik)

siqoq (see-KOK)

salumaroaq

(sah-loo-MAH-roak)

natatgonaq

(nah-tat-GO-nak)

siqoqtoaq

(see-KOK-toe-ak)

kimoaqruk

(kee-mo-AK-rook)

anyemanya

(ahn-ye-MAHN-ya)

kalutoganik

(kah-lu-toe-GAHN-ik)

kaioglaq

(kai-OHG-lak)

tumarinyiq

(too-mar-IN-yik)

qamaniq

(KAH-mahn-ik)

\begin{tabular}{ll}
\hline & $\begin{array}{l}\text { Dindye (Fort } \\
\text { Yukon, Alaska) }\end{array}$ \\
\hline $\begin{array}{l}\text { Snowcover thick enough } \\
\text { to need snowshoes }\end{array}$ & $\begin{array}{l}\text { detthlo(k) } \\
\text { (DET-thlo(k)) }\end{array}$ \\
\hline Spot blown bare of snow & Russian \\
Area of thick snow cover, & $\begin{array}{l}\text { vyduvi } \\
\text { (vih-DOO-vi) }\end{array}$ \\
\hline $\begin{array}{l}\text { zaboi } \\
\text { (ZAA-boy) }\end{array}$ \\
\hline $\begin{array}{l}\text { Animal's overnight burrow } \\
\text { in the snow cover }\end{array}$ & Finnish \\
$\begin{array}{l}\text { Kanik crystals, vertical } \\
\text { surface }\end{array}$ & (KEY-eppi) \\
$\begin{array}{l}\text { Kanik crystals, } \\
\text { horizontal surface }\end{array}$ & $\begin{array}{l}\text { Huurre } \\
\text { (HOO-rreh) }\end{array}$ \\
\hline \hline
\end{tabular}


In spring, especially in alpine regions and in the High Arctic, the long hours of intense solar radiation can melt or sublime the snowcover surface and meltwater can trickle down through the upsik and refreeze against the ground (Miller and Kiliaan 1980). This phenomenon is known to Sami reindeer herders as čuokki [CHU-ok-ki] (Eriksson 1976; Pruitt 1979). Miller and Kiliaan (1980) outlined the severe effects of Canadian High Arctic čuokki on large mammals such as Peary Caribou (Rangifer tarandus pearyi).

\section{Thickness}

Thickness is governed by latitude, proximity and direction from major sources of atmospheric moisture, as well as the regional climate. Thickness, especially in mountainous regions, can affect supranivean animals simply by hiding or "smoothing over" portions of the overwintering habitat. In steep, rocky or irregular terrain this can result in falls causing broken limbs. Murie (1935) noted the importance of snowcover in the migrations and seasonal distribution of Alaska Caribou, most of which are essentially mountain animals. Edwards and Ritcey (1959) discussed the effects of snowcover thickness on the altitudinal migrations of Moose (Alces alces) in British Columbia and Edwards (1956) correlated snowcover thickness and trends in ungulate populations. One of the classic publications in snow ecology is Nasimovich (1955) who demonstrated the influence of snowcover thickness on wintering aggregations of Moose in the Ural Mountains.

Mammals as large as Fisher (Martes pennanti) occasionally burrow into the api in a kieppi [KEY-eppi], as a hunting tactic or to escape extreme cold. Tundra mammals such as Arctic Fox (Alopex lagopus), Red Fox (Vulpes vulpes) or even Wolverine (Gulo gulo) will seek shelter by burrowing into soft spots in upsik or inside the curl-space of a snow cornice or a drift (Pruitt, unpublished observations.).

Grouse-like birds frequently use kieppi to escape low temperatures and predators (Formozov 1970; Korhonen 1980a, 1980b; Marjakangas 1986). The latter worker noted that four major factors have to be considered when defining the influence of api conditions on construction of kieppi: (1) the presence of crusts within the api, (2) the penetrability of these crusts, (3) the thickness of any soft snow on top of the crust, and (4) the total api thickness. Penetrability mainly depends on hardness and thickness of the crust. Crusts of up to 2000 to $3000 \mathrm{gm} \mathrm{cm}^{-2}$ (20 to $30 \mathrm{~N}$ ) vertical hardness are "readily penetrable," whereas harder crusts are difficult to penetrate. Therefore the minimum requirements of api conditions for use of kieppi by Black Grouse (Tetrao tetrix) in Finland are:

- When a crust which is difficult to penetrate is covered by less than $10 \mathrm{~cm}$ soft api, then Black Grouse (Tetrao tetrix) in Finland roost in trees and on the api surface, but not in kieppi. The total thickness of the api is not important.

- When there is at least $4 \mathrm{~cm}$ of soft api over a readily penetrable crust (provided that the overall thickness is at least $10 \mathrm{~cm}$ ) then Black Grouse begin to roost in kieppi as well as in trees and on the api surface.

- They roost only in kieppi when the readily-penetrable crust is covered by a layer of soft snow at least $10 \mathrm{~cm}$ thick and the total thickness of the api is about $27 \mathrm{~cm}$.

- Marjakangas (1986) concluded that Black Grouse roost in open burrows on the api surface as well as in trees when the total thickness of the api is from 10 to $26 \mathrm{~cm}$ and exclusively in kieppi when the thickness is $27 \mathrm{~cm}$ or more.

In his exhaustive study of the winter ecology of Capercaillie (Tetrao parviventris) and Black Grouse in Finland, Seiskari (1962) put the use of kieppi into context of habitat type, food supply and weather. The temperature within Willow Grouse (Lagopus lagopus) kieppi rose to at least $-6^{\circ}$ even though ambient temperature fell to $-35^{\circ}$; relative humidity was always saturated and $\mathrm{CO}_{2}$ density was never elevated above ambient (Korhonen 1980a). Andreev and Krechmar (1976) found kieppi temperatures of $-10^{\circ}$ and $-11^{\circ}$ with ambient temperatures of $-45^{\circ}$. Volkov (1968) had found similar conditions with Hazel Grouse (Bonasia bonasia) and Black Grouse (Tetrao tetrix).

Other, smaller, birds may use kieppi also: Yellowhammer (Emberiza citrinella) (Järvi and Marjakangas 1985), Common Redpoll (Carduelis flammea) and Greyheaded Tit (Poecile cinctus) (Korhonen 1980b), Snow Bunting (Plectrophanax nivalis) (Thiede 1982), Song Sparrow (Melospiza melodia) (McNicholl 1980), Marsh Tits (Poecile palustris),Willow Tits (P. montanus), Great Tits (P. major), Long-tailed Tits (Aegithalus caudata), Snow Bunting (Plectrophanax nivalis), Bullfinch (Pyrrhula pyrrhula), Common Redpoll (Carduelis flammea) (Novikov 1972) and others (Sulkava 1969; 1989). Cade (1953) reported Carduelis flammea burrowing into api not only for thermal protection but to find seeds under the surface of the api.

In periods of extreme low temperatures some birds such as the Redpolls (Carduelis flammea and C. hornemanni) continue to feed in the coldest air zone, (on the api surface), by contracting their feet and legs within the feather coat and, using their wing primaries and tail feathers, support and "roll" themselves over the api surface (Johnson 1954).

Instruments and techniques associated with thickness will be found later under the section entitled "General Procedures."

\section{Qali}

Taiga snow occurs in two phases: api [ah-PEE] or snow on the ground and qali [KAH-lee] or the snow on the trees (Pruitt 1958). In temperate regions qali is of only transitory aesthetic importance or when determining total water content. In the taiga, however, qali is a long-lasting and significant ecological factor. It has been an influence in the evolution of the shape of spruce trees; it is a powerful influence over vegetation type because it governs some aspects of forest succession (Gill et al 1973; Pruitt 1958) and it can affect humanmade structures such as powerlines by breaking them. 


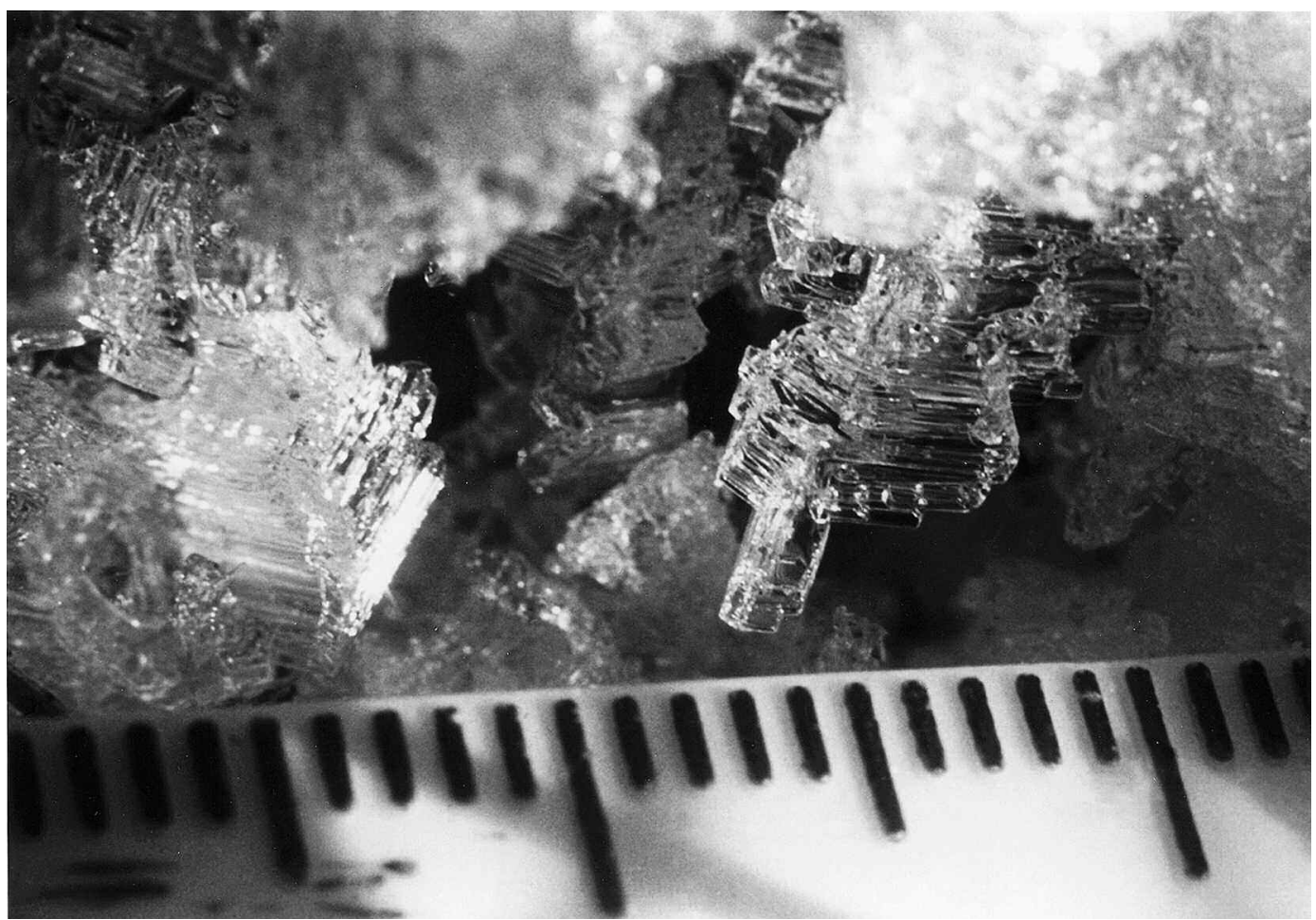

FIGURE 1. Closeup photo of subnivean space and pukak crystals. Ruler ticks are $1 \mathrm{~mm}$ apart. Manitoba, Agassiz Provincial Forest, 4 March 1978. Photo by Wolf Heck.

Qali can be quantified by means of "qalimeters," but the study of qali is in its infancy at present and the standardization of observations would be premature (Pruitt 1973). Research continues at Taiga Biological Station on characteristics and suitability of different types of qalimeters.

Qali forms best under conditions of frequent, light snowfalls, reduced incoming solar radiation and no wind. A superficially-confusing phenomenon called kanik [KAH-nik] forms when relatively warm, moisture-laden air strikes cold objects (Pruitt 1984a, Figure 5). It forms best under conditions near freezing, with light winds. Qali forms in varying amounts on horizontal surfaces, while kanik forms a layer of more-or-less uniform thickness, or sometimes spikes or needles, usually on vertical surfaces (Miller 1962, 1964, 1966). To complicate things, kanik sometimes forms on previously-deposited qali or even on the api or upsik surface. Kanik that forms on vertical surfaces is known in Finnish as huurre [HOO-rre]; on horizontal surfaces it is known as kurra [KU-rra[ (Sirpa Rasmus, personal communication).

Qali affects animals such as birds and arboreal mammals by interfering with their feeding and travel. During periods of heavy qali accumulation birds such as Pine Grosbeaks (Pinicola enucleator), Chickadees (Poecile spp.) and Red Crossbills (Loxia curvirostra) forage on windy hilltops, where qali is blown off the trees. Pine
Marten (Martes martes) and the Red Squirrel (Sciurus vulgaris) in Eurasia (Pulliainen 1973) and the North American Red Squirrel (Tamiasciurus hudsonicus) find their arboreal activities affected by heavy qali accumulation (Pruitt, unpublished data). On the other hand, some small birds such as Tits and Chickadees protect themselves from excessive radiant heat loss by huddling under lumps of qali (Steen 1958). Showshoe Hares (Lepus americanus) use snow caves formed under qalibent shrubs; thus their body radiant heat will not be lost to the infinite heat sink of the night sky (Pruitt 1984a). In contrast, qali bends shrubs over, so that their tender growing tips are brought within reach of the hares. This presents the hares with a supplementary source of food (Bider 1961).

\section{Hardness}

The snowcover that accumulates under windless conditions will be made up of flakes supported by their arms and touching each other only on the tips. Consequently most of the mass is air with relatively little ice in it. In the taiga or northern coniferous forest the snow season is characterized by little wind, a marked reduction of incoming solar energy and few incursions of mild maritime or tropical air masses. The result is a snowcover that arrives early in the autumn and lasts all winter, relatively unaffected by thaws or wind. 
Hardness $(\mathrm{H})$ is an expression of the force required to collapse the structure of the api. Most measurements of this force have been presented in detailed snow ecology publications as $\mathrm{gm} \mathrm{cm}^{-2}$. In the remainder of this paper such units will be followed by Système Internationale $(S I)$ units such as $\mathrm{Kg} \mathrm{m}^{-2}$ or Newtons $[\mathrm{N} ; 5 \mathrm{Kg}=$ $50 \mathrm{~N}]$ set off by brackets.

Hardness of taiga api can be from $\sim<2$ to $\sim 50$ gm $\mathrm{cm}^{-2}$ [ 0.02 to $\left.0.5 \mathrm{~N}\right]$. If the flakes are windblown they will be jumbled about, their fragile arms broken off and stripped and, when they come to rest, they will lie snugly against each other. Here they will also undergo metamorphosis. A snowcover of jumbled, wind-tossed and broken flakes will contain more ice. The density will still be only about 0.30 [300 $\left.\mathrm{kg} \mathrm{m}^{-3}\right]$, however. Such a snowcover is properly termed upsik [OOP-sik]. Hardness of upsik can get as high as $99000 \mathrm{gm} \mathrm{cm}^{-2}$. [990 N]. Hardness is of considerable importance to supranivean animals as large as Caribou because it can impede their movement as well as their access to subnivean vegetation (Fancy and White 1985) except under very special conditions (Pruitt 1979)

The upper part of the snowcover in a tundra or cold steppe region consists of two phases: the consolidated mass (upsik) and above it the moving snow, called siqoq [see-KOK], propelled by the wind. Siqoq periodically becomes consolidated into a sequence of drifttypes (Pruitt 1966, 1984a, 1999). The several types form and are eroded away as they reform and move over the surface of the upsik. The drift succession is known reasonably well (Pruitt 1970) but any effects of the drifts on animals (especially subnivean animals) are poorly understood. The best-known effect is that of anyemanya [ahn-ye-MAN-ya] around obstructions to the flow of air (Pruitt 1984a). Sulkava (1964) has shown that anyemanya are important in the ecology of Grey Partridge (Perdix perdix) and European Hare (Lepus europaeus) on the Ostrobothnian Plain of western Finland. Pulliainen and Iivanainen (1981) showed how distribution of snowcover, especially anyemanya, affected the winter diets and grit-gathering of Willow Grouse (Lagopus lagopus) in far northern Finland. Anyemanya are wellknown in the folk knowledge of northern peoples as places where animals congregate on the exposed vegetation or soil to obtain food or grit for gizzards. Such places are good sites for traps or snares. I have followed Arctic Fox (Alopex lagopus) as they zig-zagged across the tundra landscape, investigating one boulder-centred anyemanya after another; there is always the possibility of surprising a ptarmigan gravelling there.

Upsik occurs in two facies which have biological importance (Pruitt 1984b). Convex ground surfaces, blown clear of snow winter after winter, are called vyduvi [vih-DOO-vih] and are subject to extreme cryopedological processes. Concave ground surfaces collect snow each winter, are called zaboi [ZAH-boy] (Table 1), and are protected from temperature extremes.
Zaboi can be regulators of mesic habitats in an expanse of otherwise rather xeric conditions. Zaboi collect siqoq from over a wide area and concentrate it (as well as any contaminants attached to the siqoq particles). As the zaboi slowly melt during the summer, the meltwaters and the contained contaminants, such as radioactive particles from fallout, collect downhill of the zaboi (Osburn 1963). The meltwater nourishes wet sedge mats which absorb large quantities of it. Any contaminants, radioactive or otherwise, are immobilized by the sedges. The sedge mats are not perfect sinks, however. Eventually the sinks will "fill up" and the contaminants will flow through and enter the meltwater system. This situation deserves attention and further research because virtually every city in western and central North America gets its water supply, originally, from zaboi (Osburn 1963).

Small taiga mammals such as the voles Clethrionomys spp.or Microtus spp.or shrews Sorex spp., when unable to escape from the api surface during cold periods, can survive such conditions only a few hours. Undisturbed taiga api can have a vertical hardness range of $<3$ to $50 \mathrm{gm} \mathrm{cm}^{-2}$ [0.02 to $0.5 \mathrm{~N}$ ]. A trail made by a dozen passes of humans on skis can have a vertical hardness range of 25 to $7500 \mathrm{gm} \mathrm{cm}^{-2}$ [0.25 to $75 \mathrm{~N}$ ], but a trail made by only two passes with one person on a snowmobile can have vertical hardnesses of 550 to $7000 \mathrm{gm} \mathrm{cm}^{-2}$ [5.5 to 70N]. Moreover, a snowmobile, because of its weight and the churning action of the track, destroys the pukak layer and makes the api the same hardness throughout its total thickness (Pruitt, unpublished data). In effect, snowmobiles change api into upsik. Small mammals, when tunnelling through the layers of this highly modifed snow cover, can tumble into such trails and be unable to excavate a re-entry hole into the api.

It is clear from this discussion that it is not only the thickness or hardness of the api that can be critical but also the location of the hard layer in the snowcover.

\section{Hardness Measurements}

I have found that a kit of snow instruments should have three hardness gauges: a high-range one, with a red stripe around it (calibrated from 0 to 100), a medium-range one (calibrated from 0 to 10 ) and a verylow-range one (calibrated from 0 to 2). There should be, as well, four separate discs. The discs are snapped onto the push-rod with their smooth faces outward. The largest disc results in the reading on the calibrated end of the push-rod to be multiplied by one, the next smaller disc reading is to be multiplied by 10 , the next smaller disc is to be multiplied by 100 . The smallest disc is the cylindrical end of the push-rod itself and its reading should be multiplied by 1000 . In the snow kit there should also be an elongated narrow bar or strip that has the same effective area as the largest disc. Use of this bar enables one to sample relatively thin layers in the api, thus making the results more precise. One can dif- 
ferentiate hardnesses of, for example, six layers in a given profile instead of only four layers with the circular discs alone.

Start measuring hardness by using the medium range gauge and attaching to it the largest disc that will fit the topmost layer of the api exposed on the vertical cut face. Push the gauge and disc, horizontally, slowly and steadily against the cut face. Be sure to engage the disc and the cut face with a horizontal motion otherwise error will be produced (e.g. Brown and Theberge 1990). At first, there will be a bit of surface crumbling. Continue pushing until the crystalline structure suddenly collapses. The ratchet on the push-rod keeps the calibrations in view so that the maximum force needed can be read and recorded.

Repeat the procedure several times, each in an adjacent, fresh spot of the layer. Continue the procedure for each layer of the api. Undoubtedly you will have to use several combinations of gauges and discs to get combinations that will fit each layer and its hardness. Considerable practice is necessary in order to achieve consistently-reproducible results.

A characteristic of the snowcover which I have found useful when considering supranivean animals is vertical hardness ( $\mathrm{VH})$. Use the proper combination of gauges and discs and bring them vertically down onto the surface until the crystal structure of the surface layer collapses. Horizontally cannot be substituted for vertically in this measurement (Pruitt 1990). A useful variant of VH is vertical hardness to track depth (VHT). Choose a disc approximating the animal track in area and push it vertically down to the same depth below the surface of the snowcover that the track reaches. The Swiss "ramsonde," because of its total mass, cannot be used on soft taiga api.

\section{Density}

Density is a function of the complex history of a snowcover, from the aerial formation of the original crystals, the amount of fracturing and any possible thawing events they have undergone. The more complex the history, the denser the snowcover probably is.

Density is relatively easy to measure, even using simple "kitchen hardware." The weight of a given volume of snow is divided by that volume. The expression (D) is a ratio, expressed without units, of the amount of ice in relation to the total enclosed volume. Density of the api has three main effects on living things:

- It expresses the water content of the snowcover, which can influence the magnitude (and therefore the quality) of spring runoff. Increases in density, for example, dramatically increase the water content.

- Density can be important to the survival of subnivean organisms because it governs the insulative value of the snowcover. Increases in density dramatically decrease the insulative properties of the snowcover. Density of taiga api runs from about $0.05\left(50 \mathrm{~kg} \mathrm{~m}^{-3}\right)$ to 0.15 $\left(150 \mathrm{~kg} \mathrm{~m}^{-3}\right)$. It is very light and fluffy. In contrast, density of tundra upsik can run from about $0.15\left(150 \mathrm{~kg} \mathrm{~m}^{3}\right)$ to $0.5\left(500 \mathrm{~kg} \mathrm{~m}^{-3}\right)$.

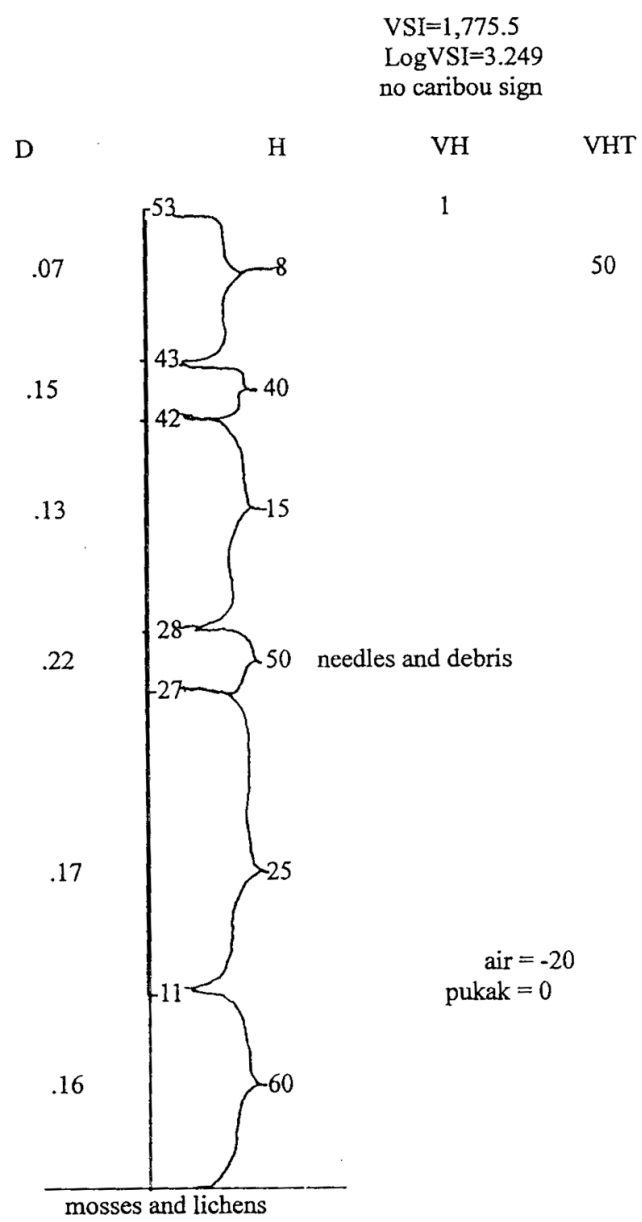

FIGURE 2. Sample data form and typical data from an api station. Station 80. 1958-02-26 Saskatchewan. 56 34' N $108^{\circ} 16^{\prime} \mathrm{W} .10 \mathrm{~m}$ from North Shore, Lake. Mature white spruce-birch. Qali breaks.

- The insulating properties of taiga api result in the pukak layer being markedly warmer than the upper layers. This warmth allows animal and bacterial activity to proceed. Such activity releases carbon dioxide in the pukak space. If the api contains dense layers the upward flow of air can be retarded and the $\mathrm{CO}_{2}$ can accumulate in concentrations up to 5 times ambient. This can result in behavioural changes in small mammals (Penny 1978; Penny and Pruitt 1984). These behavioural changes sometimes result in Clethrionomys gapperi shifting their home ranges away from the affected site and returning later when the subnivean $\mathrm{CO}_{2}$ falls to ambient concentrations.

For determining density, choose an undisturbed vertical face of the api, brush and delimit the layers, measure and record thicknesses. Start with the topmost layer. Take the Swedish density box (preferred design) by the handle, hold the box horizontally and flip the end cover up. Push the open end of the box firmly into the api horizontally until the box is full. Be careful not to overfill or force more api into the box exceeding its measured 
volume. Flip the end cover back over the end of the box. Pull the box out, scrape off any clinging snow, hang the box by the handle from the scales and note the weight. Be sure you suspend the scales by the top ring, not by holding the barrel. Subtract the tare of the box to get the weight of the enclosed snow. Divide this by 1000 to get the density. You may want to add some coils of wire solder to the handle in order to bring the tare to a figure easily divisible by 1000 .

The Swedish density box is usable for densities up to about $0.25\left(250 \mathrm{~kg} \mathrm{~m}^{-3}\right)$. For determinations above this density there are available strong, polished metal tubes, sharpened or cut into saw teeth at one end and with two small holes so that a wire loop can be attached for hanging the tube from the scales. Do not use a hammer or sledge to drive a tube into the cut face of a very hard profile because continued use will burr the butt end; carry a block of wood to use as a bumper or shield between the end of the tube and the driver.

\section{Other Data to Record}

Other characteristics useful to record are: temperature of the air, temperature of each layer, temperature of the pukak, grain type and size for each layer, subnivean plants and, of course, the standard records of date, time, weather, exact locale (UTM and/or GPS loci), vegetation type, substrate, under tree canopy or not, animal activity, name of observer.

I have found that the sample data form in Figure 2 is easy to use in the field. Make a master sheet with four replicates of the form, photocopy it as many times as required. One may use the $4 \times$ sheets held in a clip board or cut the individual forms apart with a paper cutter and keep them, in order, in a spring-loaded notebook.

One does not need to establish full api profiles. Some aspects of animal and plant winter ecology can be made clear with well-chosen hardness readings. For example, I observed (Pruitt 1984b) how Collared Lemmings (Dicrostonyx groenlandicus) made their tunnels through hard tundra upsik by excavating along a relatively soft layer floored and roofed with harder layers. It is clear that detailed knowledge of the natural history of the subject species will enable one to focus on critical features influencing its winter survival.

A "Snow Index" incorporates natural history and behavioural characteristics and correlates them with movement and behaviour of the species being considered in relation to several characteristics of the snow cover. For example, Pruitt $(1959,1981)$ showed that the distribution of $R$. $t$. groenlandicus on their winter range in northern Saskatchewan and south-central Northwest Territories could be correlated with and predicted by certain characteristics of the snow cover. Henshaw (1968) confirmed Pruitt's thresholds of sensitivity to the thickness and hardness of the snow cover in $R$. $t$. granti in northwestern Alaska. Stardom (1975) showed how the winter activity of $R$. t. caribou in southeastern Manitoba correlated closely with nival factors. Stardom also showed that the threshold of sensitivity to thickness was greater in $R$. t. caribou than in $R$. t. groenlandicus. Darby and Pruitt (1984) put the winter movements of $R$. t. caribou in the southeastern Manitoba taiga into perspective for that mid-continent taiga region.

Pruitt (1959) noted that the ideal nival winter range for $R$. $t$. groenlandicus had api that was thin, of little hardness and density, and that had not been affected by invasions of warm, moist air. In other words, their optimum winter habitat was in a cold, continental climate that enabled the heat and moisture to flow uninterruptedly from the earth through the api to the cold, dry air above. Deviations from this ideal situation result in worsening of over-wintering conditions for Caribou.

I combined hardness and thickness data (Pruitt 1979, 1981, 1989, 1990, 1992) of several layers in different combinations (based on several known aspects of Caribou winter ecology and behaviour) to arrive at what I call the Värriö Snow Index (VSI):

$\mathrm{VSI}=(\mathrm{H}>\mathrm{H} \mathrm{H} \mathrm{b} \mathrm{Tb}+\mathrm{Vs} \mathrm{Ts}+\mathrm{Hh} \mathrm{Th}) \mathrm{T}$ ta $/ 1000$

Where $\mathrm{H}>\mathrm{H}=$ Hardness of hardest layer more than halfway between the substrate and the top of the snowcover. $\mathrm{Hb} \mathrm{Tb}=$ Hardness times thickness of basal layer.

VsTs $=$ Vertical hardness of surface layer times thickness of surface layer.

$\mathrm{Hh} \mathrm{Th}=$ Hardness times thickness of hardest layer (if not $\mathrm{H}_{\mathrm{b}} \mathrm{T}_{\mathrm{b}}$ ).

(If basal layer is the hardest, then term Hh Th drops out.) $\mathrm{Tta}=$ Total thickness of the api.

Most records of api hardness in relation to Caribou have been recorded in $\mathrm{gm} \mathrm{cm}^{-2}$. Pennycuick (1974) presented factors to convert to SI units.

This index models the relations with api of several subspecies of Rangifer tarandus: (R. t. tarandus [Pruitt 1979]; R. t. groenlandicus [Pruitt 1981]; R. t. fennicus [Pruitt 1989]; R. t. caribou [Schaefer 1990]) in Scandinavia and North America. Schaefer (1996) and Schaefer and Pruitt (1991) used these techniques to determine different qualities of Woodland Caribou winter range in Manitoba.

Raine $(1983,1987)$ devised a Snow Index that modelled the relations of Marten (Martes americana) and Fisher to the surface and upper layers of the api in the taiga of southeastern Manitoba. He found that these two closely-related sympatric species utilized the habitat differently, governed in large degree by the characteristics of the api. Fisher movements were restricted in midwinter by the presence of thick, soft api. At this time of the year Fisher travelled on trails made by Snowshoe Hares (Lepus americanus) and also their own trails more than at other times during the snow season. In midwinter, Fisher tended to walk through api and to leave a body drag. On the other hand, Marten appeared to be unhindered by soft api to the degree Fisher were. Marten tracks never showed a body drag 


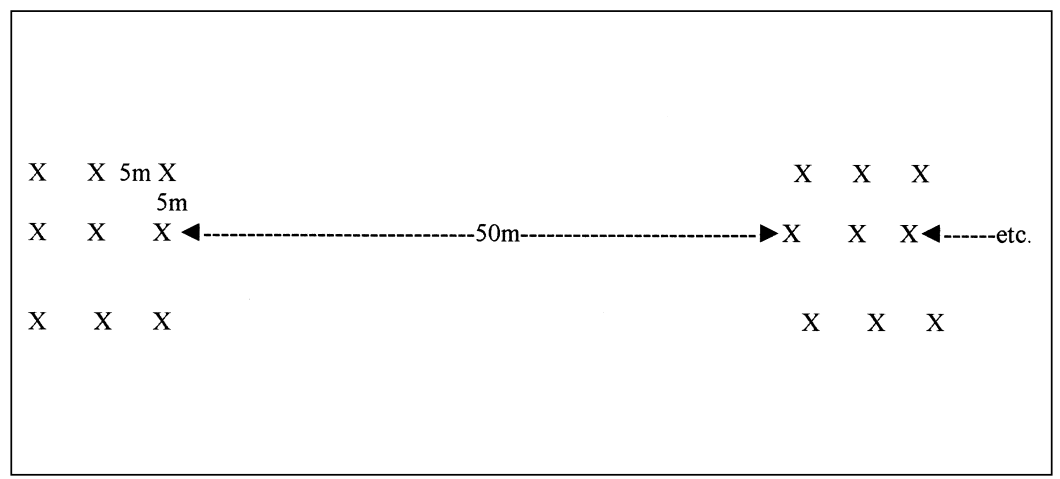

FIGURE 3. Technique of establishing a standardized survey of api thickness. Xs signify sites of actual thickness measurements.

in the api. They did use Hare trails and their own trails in midwinter but not to the extent Fisher did.

Raine's Snow Index (SI) for the top $10 \mathrm{~cm}$ of the api, in relation to Marten and Fisher is:

$\mathrm{SI}=1000-\Sigma(\mathrm{T} \times \mathrm{H})$

Where $\mathrm{T}=$ Thickness of the api in centimetres

$\mathrm{H}=$ Hardness of the top $10 \mathrm{~cm}$ in $\mathrm{gm} \mathrm{cm}^{-2}$

Both species were usually supported by $\mathrm{H}$ of $100 \mathrm{gm}$ $\mathrm{cm}^{-2}[1 \mathrm{~N}]$. This value was taken as the maximum hardness of any layer; therefore 1000 was the maximum value of the sum of the products. Any SI of near zero meant that both species could travel freely on the api surface, whereas an SI of 900 or more would perhaps indicate a hindering effect on their movements. Raine found that this SI modelled the responses of both Marten and Fisher to changes in api thickness and hardness. He also found that Fisher responded to increased SI by changing their gait while Marten were much less liable to.

There are two notable points brought out by Raine's study:

- Although these closely-related species used similar habitats in the same region they exhibited differences in habitat use associated with different responses to the api, thus allowing the two species to co-exist

- Their different responses to characteristics of the api enabled them to parcel out the food resources. Marten, being smaller and with less mass, are more subnivean, more arboreal and are more efficient predators on small mammals. Fisher, on the other hand, are better adapted to hunting larger prey such as Snowshoe Hares, Porcupines (Erethizon dorsatum) and ground-dwelling birds; indeed, they occasionally prey on Marten

Raine's study also demonstrated how detailed examination of the snowcover can clarify fundamental biological relationships. For example, a more parsimonious explanation of the mid-winter differences in habitat and behaviour of these two closely-related species is as energy-saving reactions (Formozov 1946) rather than curiosity, territorial or sexual interest as postulated by Marshall (1951) or Pulliainen (1980).

\section{General Procedure}

Sites for api profiles must be chosen according to criteria generated by the experimental design. For example, if the study is to test a null hypothesis "Snowcover (api) characteristics have no relation to Caribou overwintering sites" then one must sample the study region/area with two types of snowcover sites: "controls" which are spaced over the entire region either on a systematic grid (by relative area of available vegetation types) or by a randomization scheme, and "experimentals" which are related to actual Caribou feeding craters, resting sites or movement trails. The number of each is determined by the variance of the readings and the level of accuracy desired. It is as important to know the conditions where Caribou are not as to know where they are.

Thickness can vary widely. The more observation points on your study or sampling sites usually the better. One way of determining thickness is to establish permanent transects with permanent markers. For example, on a transect establish (before snow flies) "quadrats" of nine sampling points, points 5 metres apart in three rows of three points each (Figure 3). Mark each point with a thin wand having alternating bands of contrasting colour each $10 \mathrm{~cm}$ high plus a bottom section long enough to anchor the wand firmly into the substrate. Paint or mark the decimeter labels, oriented so that all can be seen from one spot outside the quadrat. Establish another quadrat nearby; this will be used for destructive sampling (api pits) for hardness, density and crystal characteristics. It should also be marked so that one is not liable to re-use the same pit for more than one sampling. Repeat such 9-point sampling sites every $50 \mathrm{~m}$ along the permanent transect (Figure 3).

Approach the thickness and hardness/density sites from the same direction each visit; this ensures that you do not attempt to resample the same site again. A wand or two will help to keep the sites differentiated. Frequently take record photos of the site. As a general rule, one can never take too many record photos. Use a standardized identification scheme to ensure the photos will be recorded correctly. 
Mark your ski poles with rings of brightly coloured reflecting tape each $10 \mathrm{~cm}$ apart beginning at the tip of the hand grip. Use a pole, thrust handle-down, through the api to measure its thickness every 5 or 10 "ski steps" periodically as you move between sites.

If your study region is windblown (e.g., tundra or steppe) determining thickness may be difficult. Very frequently it can be impossible to thrust a ski pole, handle first, into the hard snowcover. You may need to carry a thin, sharpened metal rod marked in decimeters to penetrate the wind-hardened snowcover. In some instances you may need to dig a series of small pits to ground level in order to expose profiles of the snowcover.

An api profile site is usually excavated so that the vertical cut face of the pit in the snowcover is downwind and oriented so that the sun shines on it at about a $45^{\circ}$ angle. This latter orientation is to emphasize the shadow relief of the snow crystals for photographic purposes. Differentiate and emphasize the layers of the api by gently stroking up and down with a wide, soft brush. Measure and record the thickness $(\mathrm{T})(\mathrm{cm})$ of each layer of the api.

\section{Precautions When Using a Snow Kit:}

- Be sure to return instruments and discs to their proper place immediately after use. If you drop one into the api you may not find it until spring.

- Record your data immediately; don't trust your memory.

- Keep the kit cold so that the instruments are at ambient temperature when you use them.

- If snow gets inside the kit, brush out as much as you can. Carry a small hand-operated sucker pump in order to clean out all the snow. Take the kit into a warm, dry place, open it up, disassemble it and give it a chance to thaw and dry overnight.

- With ambient temperatures between $+5^{\circ}$ and $-5^{\circ}$ snow may stick to metal parts and later freeze them immobile. Dry off the push-rod, scales, density box, etc. frequently under these conditions.

- Avoid touching the metal parts with bare hands. In warm weather your hands heat up the parts while in cold weather you can get frost-nipped from handling the cold metal.

The Snow Kit has had a long, evolutionary history from its original form (Klein, Pearce and Gold 1950). It continues to undergo changes. I welcome comments and suggestions as to how it can be modified to be even more useful. The actual instruments and tools needed will vary with the proposed research. For instance, I have a "complete" kit of instruments and tools for general research and teaching. I have found that density is of little or no consequence to Rangifer movements but hardness definitely is. Therefore, in my "caribou kit" I have only thickness and hardness instruments and those for temperature and crystal size as well as type reference photos.

One source of these materials is from the Science Shop at Lakehead University, 955 Oliver Road, Thunder Bay, Ontario, Canada P7B 5E1 or "Ed Drotar" $<$ ed.drotar@lakeheadu.ca>
All the instruments and tools will fit into various slots, holes and grooves in a block of fine-grain styrofoam inside a bright orange angler's "dry box," the lid of which is snubbed shut with a short length of bungee cord. My box fits nicely inside my rucksack. A shorthandled, flat-bladed aluminum shovel is lashed to the ice-axe loop of my rucksack. With a hunk of cheese and black bread, a thermos of tea and my Lappish bush skis (as well as field notebook and camera) I am outfitted for a day of snow study.

So we see that using words from cultures more closely associated with snow than our relatively povertystricken English opens a different world to our view. Not only does specialized, precise terminology open a new world for us, but specialized measurements of characteristics of the snow cover such as duration, thickness, hardness and density add precision to our observations. These specializations mean greater understanding and appreciation of adaptations of mammals and birds (as well as plants) to a phenomenon (snow) characteristic of a significant portion (winter) of the annual cycle of the seasons.

It is also clear that the study of snow ecology will enable one to make significant contributions to the natural history of all animals and plants of northern regions. The tools are available, only the thematic shift is required.

\section{Acknowledgments}

About sixty classes of undergraduate and graduate students have participated in (suffered through?) long days of repeating snow stations at Taiga Biological Station during winter field trips in Mammalogy and in Boreal Ecology. Many of these students have gone on to their own research and teaching and have contributed to our knowledge of winter ecology of mammals and birds of the taiga and tundra. I am grateful to Spencer Sealy and James Hare for critical comments on an early draft of this paper as well as to two anonymous reviewers of the penultimate draft. Spencer Sealy also guided me through recent changes in the scientific names of some northern birds. My daughter, Cheryl Ann Pruitt, has contributed her exceptional editorial skills to clarify aspects of this report. As always, my wife and field companion, Erna, has kept the whole operation from falling apart. Most "Official" organizations and funding agencies have shown a remarkable lack of interest in supporting detailed winter ecological field studies in the taiga and tundra but Canadian Wildlife Service, Värriö Subarctic Research Station, Oulanka Biological Station and the Taiga Biological Station Research Trust have supported parts of this research, for which I am deeply grateful.

Visit the Taiga Biological Station Home Page (www. wilds.mb.ca/taiga) for references to other reports on the effects of snowcover on taiga animals and plants. 
One of the outside reviewers of this paper has made a significant suggestion, because he has become "...increasingly dissatisfied with phrases such as "winter ecology", "snow ecology..." which present syntax problems such as "...Ecology of plants and animals in winter/snow..." He suggests a new word-combination to cover "the study of snow" on a par with "limnology", "entomology" and so on. This word-combination would be "chionology" and made up of "chion" (Greek for "snow") and "logy" ( Greek for "knowledge of.") This word-combination would fit in nicely with the three words "chionophile", "chioneuphore", and "chionophobe" introduced by the great Russian naturalist (and "chionologist") Alexander Nikolaevich Formozov. I agree with the suggestion.

\section{Literature Cited}

Andreev, A. V., and A. V. Krechmar. 1976. Radiotelemetric study of microclimate in snow burrows of Hazel Grouse (Tetrao bonasa sibiricus). Zoologicheskii Zhurnal 55: 113-114.

Bider, J. R. 1961. An ecological study of the Hare Lepus americanus. Canadian Journal of Zoology 39: 81-103.

Brown, W. K., and J. B. Theberge. 1990. The effect of extreme snowcover on feeding site selection by Woodland Caribou. Journal of Wildlife Management. 54: 161-168.

Cade, T. J. 1953. Subnival feeding of the Redpoll in interior Alaska. A possible adaptation to the winter. Condor 53: 4344.

Darby, W. R., and W. O. Pruitt, Jr. 1984. Seasonal movements and grouping behaviour of Woodland Caribou, Rangifer tarandus caribou, in southeastern Manitoba. Canadian Field-Naturalist 98: 184-190.

Edwards, R. Y. 1956. Snow depth and ungulate abundance in the mountains of western Canada. Journal of Wildlife Management 20: 159-168.

Edwards, R. Y., and R. W. Ritcey. 1959. Migrations of Caribou in a mountainous area in Wells Grey Park, British Columbia. Canadian Field-Naturalist 73: 21-25.

Eriksson, O. 1976. Snöförhållandenas inverkan på renbetningen. Meddelelser Växtbiologiska Institut Uppsala (2): 199 pages. + appendices.

Fancy, S. G., and R. G. White. 1985. Energy Expenditure by Caribou whilecratering in snow. Journal of Wildlife Management 49: 987-993.

Formozov, A. N. 1946. Snowcover as an environmental factor and its importance in the lives of mammals and birds. Moscow Society of Naturalists. Materials for Fauna and Flora of the USSR. Zoology, New Series 5:1-152. English translation by W. Prychodko and W. O. Pruitt, Jr., Published 1963 as Special Publication Number 1, Boreal Institute, University of Alberta.

Formozov, A. N. 1970. Snow cover and grouse-like birds.Hunting and Wildlife Management 5: 18-20.

Gill, D., J. Root, and L. D. Cordes. 1973. Destruction of boreal forest stands by snow loading: Its implication to plant succession and the creating of wildlife habitat. Kootenay Collection Research Studies in Geography, British Columbia Geography Series, Number 18, Occasional Papers in Geography: 55-70.

Henshaw, J. 1968. The activities of the wintering caribou in northwestern Alaska in relation to weather and snow conditions. International Journal of Biometeorology 12 : 21-27.
Järvi, E., and A. Marjakangas. 1987. Observations of winter resting sites of the Yellowhammer Emberiza citrinella. Ornis Fennica 62: 171.

Johnson, H. McC. 1954. Winter microclimates of importance to Alaskan small mammals and birds. Unpublished PhD. thesis, Cornell University, Ithaca, New York.

Klein, D. J., D. C. Pearce, and L. W. Gold. 1950. Method of measuring the significant characteristics of a snow cover. Ottawa, National Research Council, Committee on Soil and Snow Mechanics, Technical Memorandum Number. 18: 22 pages plus appendices.

Korhonen, K. 1980a. Microclimate in the snow burrows of Willow Grouse (Lagopus lagopus). Annales Zoologici Fennici 17: 5-9

Korhonen, K. 1980b. Temperature in the nocturnal shelters of the Redpoll (Acanthis flammea L.) and the Siberian Tit (Parus cinctus Budd.) in winter. Annales Zoologici Fennici 17: $165-168$.

Marshall, W. H. 1951. Pine Marten as a forest product. Journal of Forestry 49: 899-905.

Marjakangas, A. 1986. On the winter ecology of the Black Grouse Tetrao tetrix in central Finland. Acta Universitatis Oulunensis, Series. A, Scientiae Rerum Naturalium, Number 183, Biologica, Number 229: 87 pages.

McNicholl, M. 1980. Communal resting of Song Sparrows under snowbank. Canadian Field-Naturalist 93: 325-326.

Miller, D. H. 1962. Snow in the trees - some regional aspects. Annals of Association of American Geographers 52: 349.

Miller, D. H. 1964. Interception processes during snowstorms. U. S. Forest Service Research Paper PSW-18: 24 pages.

Miller, D. H. 1966. Transport of intercepted snow from trees during snow storms. U. S. Forest Service Resesarch Paper PSW-33: 30 pages.

Miller, F. L., and H. P. L. Kiliaan. 1980. Some observations on springtime snow/ice conditions on 10 Canadian High Arctic Islands - and a preliminary comparison of snow/ice conditions between eastern Prince of Wales Island and western Somerset Island, N.W.T. 5 May - 2 July 1979. Canadian Wildlife Service, Progress Notes, number 116: 1-11.

Murie, O. J. 1935. Alaska-Yukon Caribou. North American Fauna, Number 54: 93 pages.

Nasimovich, A. A. 1955. Role of the snowcover regime in the lives of ungulates on the territory of the USSR. Institute of Geography, Academy of Science Press, Moscow: 402 pages.

Novikov, G. A. 1972. The use of under-snow refuges among small birds of the sparrow family. Aquilo, Series Zoologica. 13: 95-97.

Olsson, P. Q., M. Sturm, C. H. Racine, V. Romanovsky, and G. E. Liston. 2003. Five stages of the Alaskan Arctic cold season with ecosystem implications. Arctic, Antarctic and Alpine Research 35: 74-81.

Osburn, W. S. 1963. The dynamics of fallout distribution in a Colorado Alpine Tundra snow accumulation ecosystem. Pages 51-71 in Radioecology. Edited by V. Schultz and A. W. Klement, Reinhold Publishing Corporation and American Institute of Biological Science (Institute of Arctic and Alpine Research, University of Colorado, Contribution Number 8).

Penny, C. E. 1978. Subnivean accumulation of $\mathrm{CO}_{2}$, its effects on the distribution of small mammals. Unpublished MSc thesis, University of Manitoba, Winnipeg: 106 pages. 
Penny, C. E., and W. O. Pruitt, Jr. 1984. Subnivean accumulation of $\mathrm{CO}_{2}$ and its effects on winter distribution of small mammals. Carnegie Museum of Natural History, Special Publication Number 10: 373-380.

Pennycuick, C. J. 1974. Handy matrices of unit conversion factors for biology and mechanics. Edward Arnold Publishers, London: 47 pages.

Pruitt, W. O., Jr. 1957. Observations on the bioclimate of some taiga mammals. Arctic 10: 130-138.

Pruitt, W. O., Jr. 1958. Qali, a taiga snow formation of ecological importance. Ecology 39: 169-172.

Pruitt, W. O., Jr. 1959. Snow as a factor in the winter ecology of the Barren-Ground Caribou (Rangifer arcticus). Arctic 12: $158-179$.

Pruitt, W. O., Jr. 1960. Animals in the snow. Scientific American 202: 60-68.

Pruitt, W. O., Jr. 1966. Ecology of terrestrial mammals. Chapter 20 (pages 519-564) in Environment of the Cape Thompson Region, Northwestern Alaska. Edited by N. J. Wilimovsky, and J. N. Wolfe. Washington, U. S. Government Printing Office, Division of Technical Information. PNE-481.

Pruitt, W. O., Jr. 1968. Synchronous biomass fluctuations of some northern mammals. Mammalia 32: 172-191.

Pruitt, W. O., Jr. 1970. Some ecological aspects of snow. Proceedings of the 1966 Helsinki Symposium on Ecology of the Subarctic Regions, UNESCO Series Ecology and Conservation 1: 83-99, Paris, 364 pages

Pruitt, W. O., Jr. 1971. Scandinavian-Canadian field workshop on Rangifer-snow ecology. Arctic 24: 145.

Pruitt, W. O., Jr. 1973. Techniques in boreal ecology. Part A Environmental analysis. Part B - Animal populations and activity. $16 \mathrm{~mm}$ colour teaching films and VHS videos produced by Instructional Media Centre, University of Manitoba.

Pruitt, W. O., Jr. 1978. Boreal ecology. Studies in Biology Number. 91, University of London, Edward Arnold, Publishers, London. iv +73 pages.

Pruitt, W. O., Jr. 1979. A Numerical "Snow Index" for Reindeer (Rangifer tarandus) winter ecology (Mammalia, Cervidae). Annales Zoologici Fennici 16: 271-280.

Pruitt, W. O., Jr. 1981. Application of the Värriö Snow Index to overwintering North American Barren-Ground Caribou (Rangifer tarandus arcticus). Canadian Field-Naturalist 95: 363-365.

Pruitt, W. O., Jr. 1984a. Snow and living things. Pages 51-77 in Northern Eology and Resource Management. Edited by R. Olson, F. Geddes, and R. Hastings, University of Alberta Press, Edmonton xvi + 438 pages.

Pruitt, W., O., Jr. 1984b. Snow and small mammals. Carnegie Museum of Natural History, Special Publication Number 10: $1-8$.

Pruitt, W. O., Jr. 1989. Application of the Värriö Snow Index to overwintering wild Forest Caribou (Rangifer tarandus fennicus) in eastern Finland. (Mammalia, Cervidae). Aquilo, Series Zoologica. 24: 13-20.

Pruitt, W., O., Jr. 1990. Clarification of some api characteristics in relation to Caribou (Rangifer tarandus). Rangifer, Special Issue, Number 3: 133-137.

Pruitt, W. O., Jr. 1992. Quantitative differentiation of types of feeding craters of Rangifer tarandus. Rangifer 12: 29-32.

Pruitt, W. O., Jr. 1999. Formozov-inspired concepts in snow ecology in North America. Bulletin Moscow Society of Naturalists 104(3): 13-22. [Memorial Volume on the Hundredth Anniversary of the Birth of Alexander Nikolaevich Formozov; in Russian and English.]
Pulliainen, E. 1973. Winter ecology of the Red Squirrel (Sciurus vulgaris) in Northeastern Lapland. Annales Zoologici Fennici 10: 487-494.

Pulliainen, E. 1980. Winter habitat selection, home range and movements of the Pine Marten in Finnish forest Lapland. Värriö Subarctic Research Station, Report Number 16: 271-280.

Pulliainen, E., and J. Iivanainen. 1981. Winter nutrition of the Willow Grouse Lagopus lagopus in the extreme north of Finland. Annales Zoologici. Fennici 18: 263-269.

Raine, R. M. 1983. Winter habitat use and responses to snow cover of Fisher (Martes pennanti) and Marten (M. americana) in southeastern Manitoba. Canadian Journal of Zoology 61: 25-34.

Raine, R. M. 1987. Food habits and foraging behaviour of Fisher (Martes pennanti) and Marten (M. americana) in southeastern Manitoba. Canadian Journal of Zoology 65: 745-747.

Schaefer. J. A. 1990. Canopy, snow and lichen on Woodland Caribou range in southeastern Manitoba. Lakehead Centre for Northern Studies, Research Report Number 20: 18-99

Schaefer, J. A. 1996. Canopy, snow and lichens on Woodland Caribou range in southeastern Manitoba. Rangifer, Special Issue Number 9: 239-243.

Schaefer, J. A., and W. O. Pruitt, Jr. 1991. Fire and Woodland Caribou in southeastern Manitoba. Wildlife Monographs, Number 116: 39 pages.

Schemenauer, R. S., M. O. Berry, and B. Maxwell. 1981. Snowfall formation. Chapter 4 (pages 129-152) in Handbook of snow. Edited by D. M. Gray and D. Male. Pergamon Press, Toronto, Oxford. 776 pages.

Seiskari, P. 1962. The winter ecology of Capercaillie (Tetrao urogallus) and the Black Grouse (Lyrurus tetrix) in Finland. Riistatieteellisiö julkaisiya 22: 1-119.

Seligman, G. 1936. Snow structure and ski fields. MacMillan Co., London: 555 pages.

Stardom, R. R. P. 1975. Woodland Caribou and snow conditions in southeast Manitoba. First International ReindeerCaribou Symposium, Proceedings: 324-334.

Steen, J. 1958. Climatic adaptations in some small northern birds. Ecology 39: 625-629.

Sturm, M. 1992. Snow distribution and heat flow in the taiga. Arctic and Alpine Research 24: 145-152.

Sturm, M., J. Holmgren, G. E. Liston. 1995. A seasonal snow cover classification for local to global applications. Journal of Climate 8: 1261-1283.

Sulkava, S. 1964. On the living conditions of the Partridge (Perdix perdix) and the Brown Hare (Lepus europaeus) in Ostrobothnia. Aquilo, Series Zoologica 2: 17-24.

Sulkava, S. 1969. On small birds spending the night in the snow. Aquilo, Series Zoologica 7: 33-37.

Sulkava, S. 1989. Resting places of the Mountain Hare Lepus timidus in winter. Aquilo, Series Zoologica 24: 95-98.

Thiede, W. 1982. Snow Bunting Plectrophanax nivalis roosting in snow. Ornis Fennica 59: 37-38.

Volkov, N. I. 1968. An experimental study of the thermal conditions in snow burrows of tetraonid birds. Zoologicheskii Zhurnal 47: 283-286.

Whitney, P., and D. Feist. 1984. Abundance and survival of Clethrionomys rutilus in relation to a snow-cover in a forested habitat near College, Alaska. Carnegie Museum of Natural History, Occasional Publications Number 10: 113-119.

Received 8 December 2003

Accepted 7 March 2005 